\title{
Photovoltaics in Agriculture: A Case Study on Decision
}

\author{
Making of Farmers
}

Thomas Brudermann, Kathrin Reinsberger, Anita Orthofer, Martin Kislinger \& Alfred Posch

$$
\text { University of Graz }
$$

Institute for Systems Science, Innovation \& Sustainability Research

Merangasse 18/1, 8010 Graz, Austria

\section{Corresponding author}

DI Dr. Thomas Brudermann

Mail: Thomas.Brudermann@uni-graz.at

Phone: +43 316 380-7336

Postal: Merangasse 18/1, 8010 Graz, Austria

\section{Important Note}

This is a preprint version of the following paper:

Brudermann T, Reinsberger K, Orthofer A, Kislinger M, \& Posch A (2013). Photovoltaics in Agriculture: A Case Study on Decision Making of Farmers. Energy Policy 61:96-103, doi:10.1016/j.enpol.2013.06.081.

Original version: www.sciencedirect.com/science/article/pii/S0301421513005880 


\begin{abstract}
This paper aims to identify the success factors, incentives, barriers and challenges in the adoption process of photovoltaics (PV) in the agricultural sector, with particular focus placed on decision making of individual farmers and network effects. We investigated a successful case of an Austrian farmers' association that set up a community power plant concept and a society for facilitating PV adoption among farmers. We found that PV adoption decisions are driven by economic and environmental considerations and that while ethical considerations are relatively strong among farmers, they cannot be used as predictors in the decision making process. Results furthermore suggest that while adoption of PV increases belief in technological progress as a solution to environmental problems, it may simultaneously lead to a weakening in the belief that underlying lifestyle changes are necessary. Our conclusions address crucial aspects of PV adoption in agriculture, and implications for policy measures related to respective community initiatives.
\end{abstract}

Keywords: PV adoption, PV in agriculture, community renewables 


\section{Introduction}

As in many other domains, agriculture also faces the problem of increasing dependency on energy sources such as electricity, oil, natural gas or coke (Karkacier et al., 2006). The agricultural sector is characterized by a high energy demand, e.g. energy is needed for operation of vehicles and irrigation pumps, air-conditioning of greenhouses, barns, warehouses and other farm buildings, etc. (Ozkan et al., 2004). At the same time agriculture is well-suited to meeting energy demand directly since natural resources such as biomass and biogas are readily available and small scale power generation based on renewable energy sources is often quite possible. That the use of photovoltaic systems (hereafter PV), which is the predominant electrical renewable technology for decentralized production (Bagnall and Boreland, 2008), is rapidly gaining ground in agriculture should thus come as no surprise. Areas which are not used for farming, or large buildings with flat roofs, offer ideal conditions for the installation of PV plants (Bayod-Rújula et al., 2011).

Given the relatively high energy demands of the sector, and the potential impact that climate change might have on agricultural, the increased adoption of renewables in the farm community seems a natural response. Early research in this field by Jarach (1989) outlined the barriers to the diffusion of renewables in agriculture over 20 years ago. While his research demonstrated the importance of economic barriers, e.g. ability to compete effectively with conventional energy sources, various operational barriers were also found to be relevant. As a result, in the 1990s relatively little attention was paid to the application of PV in the agricultural sector, and only few studies were undertaken. Research at this time mainly focussed on technological possibilities and on initial small-scale experiments in ventilation, water pumping and irrigation (e.g. Reuss et al., 1990).

Larger-scale PV adoption in agriculture has only begun to appear in more recent years, facilitated by on-going technological progress and the related substantial fall in costs. In their comprehensive review of various solar and photovoltaic systems, Mekhilef et al. (2013) conclude that photovoltaic systems and/or solar thermal systems would be very suitable options for a variety of agricultural applications in irrigation, cooling and storage, drying, etc., as well as in the field of solar greenhouses. When it comes to small-scale applications in remote locations, where electricity is not easily accessible via the grid, PV is a particularly suitable solution (Meah et al., 2008). Bayrakci and Kocar (2012) also mention the possibility of PV application in soil solarisation, a non-chemical technique which controls many soilborne pathogens and pests, and Smyth (2012) discusses the concept of the "solar winery", where solar renewables offer a complimentary solution to many winegrowing processes.

To sum up, the existing literature suggests a series of possible applications for PV in agriculture. The practical question that thus needs to be addressed is under what circumstances do individual farmers actually decide to adopt PV, and what role does interaction among and between farmers or other actors play in such decisions? Research on decision making regarding PV systems has so far mainly focused on households and individual consumers as well as on the respective incentives, constraints etc. that actors face (Faiers and Neame, 2006; Haas et al., 1999; Jager, 2006; Palm and Tengvard, 2011). Buying a 
photovoltaic system demands high individual involvement since it is probably a decision that people make only once in their lives (Jager, 2006). At early decision-making stages, expert support or people already in possession of a PV system may serve as advisors. Social processes serve to facilitate the exchange of information, i.e. contact with a friend or neighbor who has successfully installed a PV system. This applies to both the satisfaction one derives from owing a PV system, as well as to coping with technical and administrative procedures (Jager, 2006). Consequently, network effects play a clear role in the adoption process. The more people within a certain social network have already adopted a PV system, the lower the barriers for other people in the same network. When it comes to entrepreneurial decision making, i.e. in our case, decision making by farmers, one would expect a higher weight to be placed on economic incentives than is true in the case of residential household installations, where concern for the environment and displaying environmental consciousness are more likely to dominate (Haas et al., 1999; Palm and Tengvard, 2011). Unfortunately however, owing to the relative sparsity of studies, clarity on this issue is not possible at the moment.

The aims of our paper are hence as follows: While incentives and constraints in the adoption of PV by households have been addressed by previous studies, the focus here is placed on the adoption of PV in the agricultural sector. Our study analyses an existing successful case and aims to identify the specific success factors, incentives, barriers and challenges etc. which emerge in the adoption process. We pay particular attention to the decision making processes of individual farmers. The underlying case is a citizen-power-plant-like concept developed by an association of farmers in rural Austria. The PV concept utilizes the ideal conditions found on many farms (e.g. flat roofs, available space). In order to implement the concept, the farmers' association founded a cooperative PV society and attracted close to 150 members within a short time span of only a few months. This comparatively rapid level of diffusion makes for an interesting case study. Our main research questions are:

- What are the central incentives for and barriers to PV adoption in the case under investigation?

- What are the respective roles of economic and environmental considerations?

- Do farmers who adopt PV, and farmers who do not, all consider the same factors in the decision making process?

- What lessons can be learned for the diffusion of similar initiatives in the future?

The remainder of the paper is structured as follows: The next section introduces the case and describes the PV adoption concept investigated. Section 3 outlines our methodological approach, while section 4 summarizes and discusses the results. We focus on how and why farmers do or do not decide to join the PV society and investigate the communication channels and network effects which foster the diffusion of PV. Conclusions are then drawn in the final section of the paper. 


\section{The Cooperative PV Society of machinery ring "Hartbergerland"}

In comparison with the US or other EU member states, the agricultural sector in Austria is characterized by rather small structures. The average size of the agricultural area per farm is 42.4 hectares, with more than $70 \%$ of farms farming less than 30 hectares (Statistik Austria, 2010). Hence, for many farmers it is inefficient to own expensive technical equipment or to employ permanent personnel. These issues are addressed by the "machinery ring" ("Maschinenring"), which represents a nation-wide association of farmers offering community machinery, equipment for rental, personnel leasing and common ordering of operating supplies to its members. Approximately half of the arable land in Austria is currently farmed by the 78000 members of the machinery ring. As indicated in figure 1, the machinery ring consists of eight divisions (one per federal state, with the exception of Vienna), with largely self-dependent sub-divisions at the regional level.

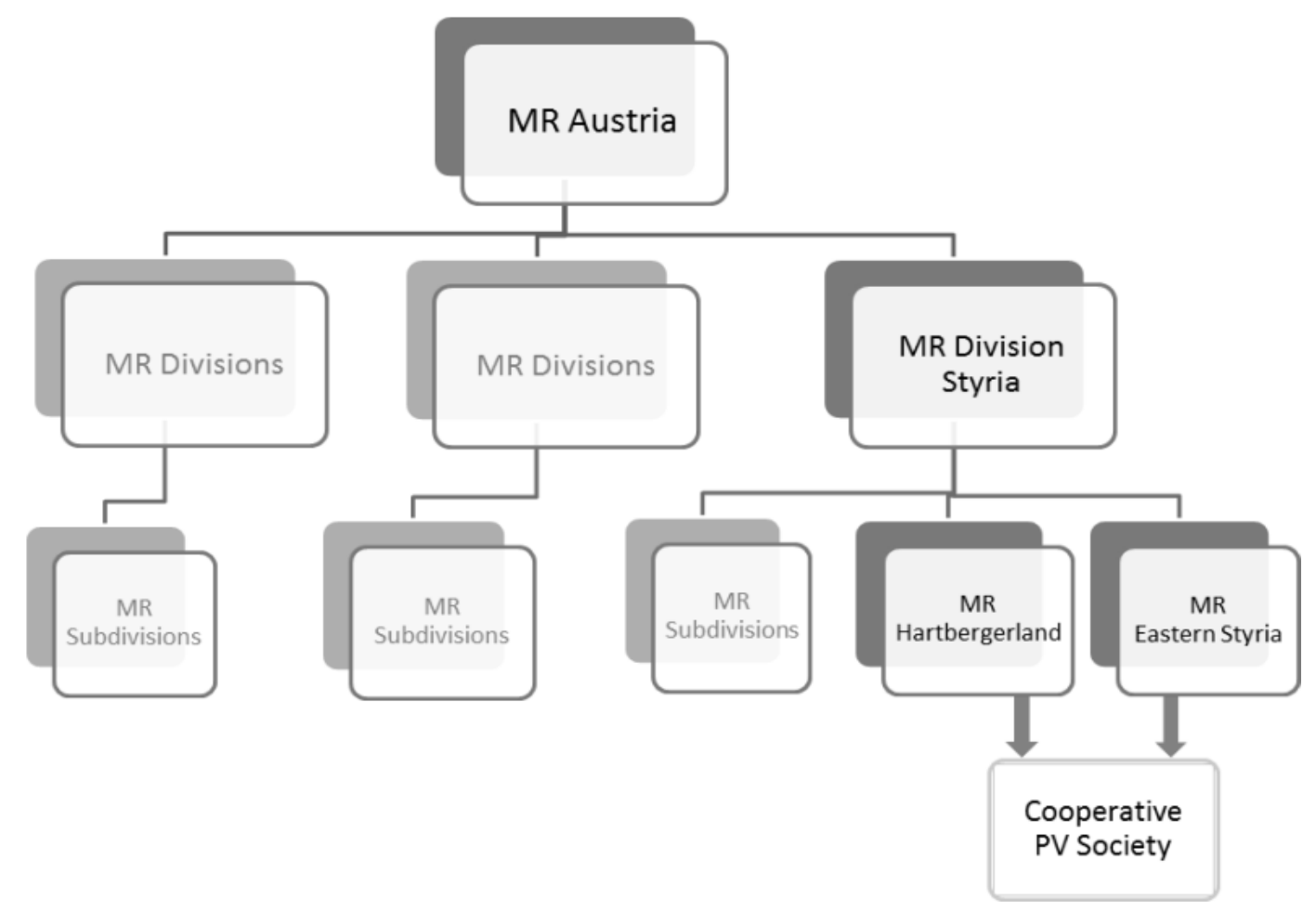

Figure 1: Structure of the Machinery Ring (MR) Austria

In 2010, two regional subdivisions of the machinery ring in Hartberg and Eastern Styria founded a cooperative society for installing PV plants. The cooperative society is a legal hybrid combining the characteristics of a limited private partnership and a limited liability company ${ }^{1}$. Thus, the PV society can be considered as a sustainability-related, bottom-up, agricultural community initiative, set up by CEOs of the two machinery ring subdivisions. While it is often difficult in practice to organize a community around a specific issue

\footnotetext{
${ }^{1}$ The legal form of the society is 'Gesellschaft mit beschränkter Haftung \& Compagnie Kommanditgesellschaft' (abbreviated ' $\mathrm{GmbH} \&$ Co. KG'). This hybrid of Limited Private Partnership and Limited Liability Company is used in some European legal systems, for example in Germany and Austria, and very common for community power plants.
} 
(Malhotra, 2006), and establishing a community energy project involves many complexities (Walker, 2008), the success of the machinery ring initiative makes it a case well worthy of study.

In order to join the PV society, membership in the machinery ring is required. Farmers who join the PV society, and hereby become Limited Partners of the society, are provided with multi-level assistance for the construction of a PV plant on their own farm buildings. This involves various legal and practical issues such as expert assessment of plant location, processing applications for subsidized feed-in tariffs, setting up contracts with grid-providers, applying for building permits and financial advice, ordering panels and carrying out the installation, etc. Within a couple of months close to 150 farmers had joined the PV society, which is quite a considerable number for rural Austria. The region under consideration has a size of approximately 2300 square kilometres and is inhabited by around 180000 people $\left(\sim 78\right.$ per $\left.\mathrm{km}^{2}\right)$.

While the society remains the legal owner of the PV installations, the Limited Partners, i.e. the farmers, receive a profit share on an annual basis and also have the option to buy the plant after the subsidized feed-in tariff expires. Due to collective ordering of a high number on modules, and to the labour contributed by the farmers together with machinery ring staff, substantial cost savings are achieved (up to $25 \%$ to comparable installations). Farmers have to finance only $20 \%$ of the net investment with equity capital; the rest can be financed with a long-term loan from the machinery ring.

In Austria, feeding in electricity into the grid from renewables such as wind, hydro or PV is under certain circumstances subsidized with above-market-price feed-in tariffs. The tariffs for new installations are redetermined annually according to the development of the market costs for PV installations and are then guaranteed for the following 13 years. The guaranteed feedin tariff depends on plant size and type. For example, roof-top PV installations with a capacity of 15-20 kWp received the highest feed-in tariffs in 2011 and 2012, with up to $€ 0.296$ ( US$\$ 0.39$ ) per $\mathrm{kWh}$, and were consequently the most popular choice among PV society members $^{2}$. This regulation significantly reduces the cost risk for small-scale electricity producers. After funding expires, private electricity producers might continue feeding in electricity at market prices, or use the electricity produced themselves.

On average, financial break-even for these PV-installations is expected after 10-12 years, depending on the size of the installation and electricity yield. This includes the cost of inverter replacement after 12 years. This rather short payoff time is due to discounts offered for bulk ordering, tax concessions for farmers, and the inclusion of the aforementioned subsidies. The investment breaks even before the guaranteed feed-in tariff expires and literally produces electricity almost for free after year 12 (modules have an expected lifetime of 25 years). The average annual solar radiation in the respective region is approximately $1150 \mathrm{kWh} / \mathrm{m}^{2}$

\footnotetext{
${ }^{2}$ In 2013 , the subsidized feed-in tariff for new installations was reduced to $€ 0.18$ per $\mathrm{kWh}$. The available volume is capped and distributed on a "first come - first served" basis.
} 
according to the Austrian Energy Agency ${ }^{3}$, a value slightly above the European average of $1096 \mathrm{kWh} / \mathrm{m}^{2}$.

\section{Methods}

In order to answer our research questions, we applied a two-stage study design. In an initial exploratory step we conducted semi-structured interviews with the two initiators and with 16 randomly chosen members of the PV society. The interviews were carried out in December 2011 and January 2012.

Based on the interview outcomes we then developed several hypotheses and designed a questionnaire to test them. The questionnaire aimed at gathering data concerning (1) demographics and farm characteristics (2) general environmental problem awareness (3) motives for adopting or not adopting photovoltaic systems, and (4), explored the importance of the machinery ring and social networks within the adoption process. In order to measure (2) - (4) we designed appropriate items and applied 6-level scales. The postal survey was conducted between September and November 2012. Respondents were asked to complete the questionnaire carefully and to return it using a pre-paid envelope. Anonymity and confidentiality were guaranteed but respondents were also given the option of providing contact details for a follow-up investigation. The study population consisted of 1,878 members of the machinery ring in the respective area, i.e. the district of Hartberg. After excluding non-farming members ${ }^{4}$ - e.g. NPOs, companies, public authorities like municipalities - 1,690 members remained in our study population. We divided the study population into two naturally distinct groups:

1. Adopters of a residential photovoltaic installation, who at the time of the survey were members of the PV society ( $\mathrm{N}=148)$. Questionnaires were sent to all 148 members and a total of $n=67$ respondents returned the questionnaires, resulting in a response rate of $45.3 \%$. The respondents had joined the initiative in 2011, and their plants entered into service between November 2011 and September 2012.

2. Non-adopters, i.e. farmers who were members of the machinery ring, but were not yet members of the PV society ( $\mathrm{N}=1542)$. Questionnaires were sent to 685 randomly chosen farmers from this group. A total of $n=129$ respondents returned the questionnaires, yielding a response rate of $18.8 \%$.

While parts of the questionnaire were identical for both groups, adopters were additionally questioned concerning their decision making process prior to joining the initiative. Nonadopters were asked whether they were aware of the PV initiative, and depending on their answer they were then questioned concerning their decision not to join the initiative. Out of

\footnotetext{
${ }^{3}$ See calculation tool available at www.pvaustria.at/content/page.asp?id=291 and PVGIS data available at re.jrc.ec.europa.eu/pvgis (accessed January 30, 2013).

${ }^{4}$ Companies, public authorities such as municipalities, as well as private citizens, are also allowed to join the machinery ring. Since these members are not relevant for our research questions, we excluded them from the population. According to machinery ring representatives, approximately $90 \%$ of machinery ring members are farmers.
} 
129 responding non-adopters, $104(80.6 \%)$ were aware of the initiative. Both samples consisted of farmers with mainly mixed operation modes (animal husbandry 63.3\%, arable farming $59.2 \%$, forestry $47.4 \%$, fruit cultivation $14.3 \%$ ).

A standard statistical software package, SPSS 20, was used to analyse the results. In a first step we used descriptive statistics to evaluate response frequencies (median values were calculated from grouped data). Then we applied non-parametric tests to compare the medians of the observed variables across the two groups - the Mann-Whitney U-Test for independent variables and the Wilcoxon Test for dependent variables.

In our additional observations we looked for the presence of coherencies between specific attitudes and the decision to adopt PV. The focus of this analysis was to pinpoint those independent variables which best predict PV adoption. Factors considered were environmental awareness, status thinking, underlying motivations and concerns, and farm experience.

\section{Results of the qualitative interviews}

Although the information gained from the qualitative interviews covers potential success factors and various individual motivations for adopting PV in agriculture, it also points to a series of barriers and problems. Three key, and partly overlapping, incentives for joining the PV society are worthy of mention here. Firstly, some farmers are driven by idealism, ecoattitudes and environmental awareness, even though only relatively few of them are organic farmers. Farmers motivated by strong eco-attitudes may still participate even in the absence of a financial gain. Secondly, and more prominently, monetary incentives play a strong role: Farming is energy-intense and owning a PV plant may be seen as a first step towards energy autarky and independence from energy companies. It is often regarded as a safe and meaningful investment, or even a private pension plan in unsecure times. Thirdly, a PV plant might, depending on its size, also represent a status symbol. With respect to the motivations of the initiators of the PV society, the main drivers were securing the financial future of their subdivision of the machinery ring, which depends on membership fees, and a personal interest in the technology.

Among the barriers or constraints to adoption, respondents mentioned non-cooperative building experts from municipal governments, problems with building permits, long decision times in regional governments regarding grant notification, as well as a significant reduction of subsidized feed-in tariffs during the founding process of the society (although the latter was offset to some extent by the rapid decline in module costs over the same time period). Additionally, de-centralized energy production is at odds with the interests of electricity suppliers, who frequently delayed the connection to the electricity grid, or charged high fees. This appears to be a local problem which does not seem to be prevalent in other federal states of Austria.

Besides the popular information evenings organised by the CEOs of the machinery ring subdivision, word of mouth also seems to be an important information channel for potential 
adopters. Interested farmers gather a large amount of information from neighbours and friends who have already installed a system. This is in line with a common risk management strategy in situations of uncertainty, namely evaluating risks and prospects based on the experiences of others (Fenzl \& Brudermann, 2009). Here, the high visibility of the panels plays a key role since it attracts attention from neighbours and friends.

The qualitative results furthermore suggest that trust is a crucial success factor. The cooperative society of farmers is a highly respected and trusted institution in the region, and has been so for many years. Several members stated that they would not have joined the PV society if it had been founded by an organization other than the machinery ring. Based on the qualitative outcomes we then conducted a quantitative survey. This yielded deeper insights into the deliberations of farmers and their underlying attitudes.

\section{Results of the quantitative survey}

\subsection{Motives for PV adoption}

Adopters were questioned concerning the relative importance of specific motives when deciding to adopt a PV plant, and non-adopters were questioned concerning the importance of the same motives when considering a future decision to join the PV society (which also entails investing in PV). Responses to the questions were graded on a 6-point ordinal scale from 1 (unimportant) to 6 (very important). The results are presented in table 1 .

The most important motives reported by adopters related to sustainability, i.e. responsibility towards future generations, and PV as an alternative to nuclear power. One economic argument was also thought important, i.e. the payback period being less than 13 years. 
Table 1: Motives - Descriptive Statistics/Mann-Whitney U-Test

\begin{tabular}{lcccccc}
\multicolumn{1}{c}{ (potential) motives } & \multicolumn{2}{c}{ adopters } & \multicolumn{2}{c}{ non-adopters } \\
\hline & $\mathrm{n}$ & Median $^{\text {b) }}$ & $\mathrm{n}$ & Median $^{\text {b) }}$ & $\begin{array}{c}\text { asympt. } \\
\text { sign. }^{\text {c) }}\end{array}$ \\
\hline responsibility for future generations $^{\text {a) }}$ & 66 & 5.82 & 108 & 5.57 & $0.003^{* *}$ \\
alternative to nuclear power $^{\text {a) }}$ & 67 & 5.70 & 108 & 5.71 & 0.967 \\
payback period less than 13 years $^{\text {a) }}$ & 67 & 5.69 & 105 & 4.40 & $0.000^{* * *}$ \\
clean technology $^{\text {a) }}$ & 67 & 5.67 & 107 & 5.59 & 0.424 \\
own generation of electricity after year 13 $^{\text {a) }}$ & 67 & 5.57 & 105 & 4.59 & $0.000^{* * *}$ \\
lower electricity costs after year 13 $^{\text {a) }}$ & 67 & 5.57 & 105 & 4.69 & $0.000^{* * *}$ \\
promote a future technology $^{\text {a) }}$ & 66 & 5.37 & 105 & 5.28 & 0.503 \\
independence from electricity tariffs / companies $^{\text {a) }}$ & 67 & 5.36 & 107 & 5.17 & 0.196 \\
secure investment $^{\text {a) }}$ & 67 & 4.92 & 108 & 3.76 & $0.000^{* * *}$ \\
fascinating technology $^{\text {a) }}$ & 66 & 4.62 & 106 & 3.94 & $0.012^{*}$ \\
being a role model $^{\text {a) }}$ & 66 & 4.03 & 106 & 3.80 & 0.300 \\
\hline
\end{tabular}
a) 6-level scale (6 very important - 1 unimportant)
b) Calculated from grouped data
c) $* * * \mathrm{p}<.001, * * \mathrm{p}<.01, * \mathrm{p}<.05$

The Wilcoxon's test, which is a nonparametric test for assessing whether two related samples differ significantly in their central tendency, confirms the high relevance of these three motives. They are significantly higher rated than other motives, such as promoting a future technology $(\mathrm{z}(\mathrm{n}=67)=-3.114, \mathrm{p}=0.002<0.01)$. Part of the explanation for this probably lies in the fact that anti-nuclear energy attitudes are common in Austria.

Asking non-adopters about potential motives for adoption yielded similar results, with alternative to nuclear power, clean technology and again responsibility for future generations being the strongest motives, showing high significance $(\mathrm{z}(\mathrm{n}=129)=-2.595, \mathrm{p}=0.009<0.01)$. In general, although the median ratings for motives found among adopters tended to be slightly higher than those for non-adopters, overall the ratings were in fact very similar. In fact there is a significant positive correlation between the grading of the motives by adopters and non-adopters.

The Mann-Whitney U-Test, a nonparametric test for assessing whether independent samples differ significantly in their central tendency (similar to the Student's t test for metric data), shows that there are highly significant differences between the two groups, mainly when it comes to economic factors - the short payback period $(\mathrm{z}(\mathrm{n}=67)=-7.284, \mathrm{p}=0.000<0.001)$, lower electricity costs $(\mathrm{z}(\mathrm{n}=67)=-4.813, \mathrm{p}=0.000<0.001)$ and secure investment $(\mathrm{z}(\mathrm{n}=67)=-4.454, \mathrm{p}=0.000<0.001)$. While motives related to environmental and ethical considerations are reported to be very important in the decision making process, they, in contrast to economic motives, fail to predict PV adoption. 
A clear limitation here relates to the fact that respondents were asked to describe the factors entering their decision making process post-hoc, i.e. several months after they actually had made the decision. We know that in reality often only a relatively small number of factors actually contribute to a decision (Gigerenzer \& Gaissmaier, 2011). Many factors may simply be added as a form of post-hoc rationalization, or as an attempt at raising the overall credibility of the decision.

In order to gain further insight into these matters, we asked those non-adopters who were aware of the initiative $(n=101)$ whether they had had concrete plans to join the PV initiative within the coming months. In total, 25 respondents confirmed having such plans (henceforth called "future-joiners"), while 76 respondents did not have such plans (hereafter called "nonjoiners"). Being, in a temporal sense, relatively close to making a decision to join the PV initiative, the group of "future joiners" is obviously of particular interest in our research. Comparing the relative importance of motives for future joiners with the potential motives for non-joiners yields significant differences. For the various motives offered in table 1, we found the following: payback period less than 13 years (future-joiners median 4.93 vs. non-joiners median 4.03, $\mathrm{z}=-2.807, \mathrm{p}=0.005<0.01)$, being a role model $(4.46 / 3.34, \mathrm{z}=-2.543$, $\mathrm{p}=0.011<0.05)$, own generation of electricity after year $13(5.29 / 4.20, \mathrm{z}=-2.708$, $\mathrm{p}=0.007<0.01)$ and lower electricity costs after year $13(5.25 / 4.30, \mathrm{z}=-2.409$, $\mathrm{p}=0.016<0.05)$. Hence, there are clear differences in economic motives as well as in social and personal motives. Interestingly, being a role model seems to be a stronger motive before the decision is made, as compared to the post-hoc deliberations of those who already adopted PV. The other motives of future adopters are quite similar to motives reported by adopters. A word of warning is needed however: the relatively small size $(n=25)$ of the group only allows for a very limited degree of interpretation.

\subsection{Respondent concerns, reservations and doubts}

In general respondents' concerns regarding joining the PV society were rather limited. In the group of adopters, respondents rated concerns or doubts as being less significant than motives. This was also true of non-adopters, but the difference between importance of motives and concerns was smaller in this group. 
Table 2: Concerns - Descriptive Statistics/Mann-Whitney U-Test

\begin{tabular}{lcccccc}
\multicolumn{1}{c}{ concerns } & \multicolumn{3}{c}{ adopters } & \multicolumn{3}{c}{ non-adopters } \\
\hline & $\mathrm{n}$ & Median $^{\text {b) }}$ & $\mathrm{n}$ & Median $^{\text {b) }}$ & $\begin{array}{l}\text { asympt. } \\
\text { sign. }\end{array}$ \\
\hline investment volume $^{\text {a) }}$ & 67 & 4.16 & 104 & 4.28 & 0.600 \\
uncertainty regarding amount and time of funding $^{\text {a) }}$ & 67 & 3.92 & 101 & 4.52 & 0.111 \\
decline in performance over time $^{\text {a) }}$ & 67 & 3.19 & 102 & 3.36 & 0.999 \\
problems with electric power companies $^{\text {a) }}$ & 66 & 3.17 & 102 & 3.05 & 0.724 \\
expected problems with approval procedure $^{\text {a) }}$ & 67 & 3.09 & 100 & 3.61 & 0.301 \\
financial uncertainty $^{\text {a) }}$ & 66 & 3.20 & 102 & 3.44 & 0.483 \\
susceptibility to extreme weather conditions $^{\text {a) }}$ & 67 & 2.78 & 103 & 3.33 & 0.088 \\
potential malfunctioning $^{\text {a) }}$ & 66 & 2.39 & 104 & 2.59 & 0.576 \\
maintenance issues $^{\text {a) }}$ & 67 & 1.91 & 104 & 2.33 & 0.094 \\
trust in technology $^{\text {a) }}$ & 66 & 1.98 & 103 & 2.32 & 0.161 \\
\hline
\end{tabular}

a) 6-level scale (6 very important - 1 unimportant)

b) Calculated from grouped data

c) $* * * \mathrm{p}<.001, * * \mathrm{p}<.01, * \mathrm{p}<.05$

As indicated in table 2, respondents in both groups indicated a certain amount of concern regarding financial issues, i.e. the necessary investment volume and uncertainty regarding the amount and time of funding - but there was no significant diversity between the groups. There were hardly any worries concerning the technology, i.e. regarding trust in technology, maintenance issues or potential malfunctioning. As in the analysis of motives, we examined the differences between "future joiners" and "non-joiners" (those who did not plan on joining the initiative). Significant differences could only be found with respect to economic motives. Thus: investment volume (future-joiners median 3.36 vs. non-joiners median $4.44, \mathrm{z}=-2.692$, $\mathrm{p}=0.007<0.01)$, financial uncertainty $(2.73 / 3.60, \quad \mathrm{z}=-2.194, \mathrm{p}=0.028<0.05)$ and uncertainty regarding funding $(3.56 / 4.76, \mathrm{z}=-2.501, \mathrm{p}=0.012<0.05)$. There were no notable differences regarding the other types of concerns listed.

One noticeable observation is that not one single respondent in the adopters-group regrets deciding in favour of a PV system. 87\% state that the decision was a good one. Moreover $78 \%$ state that the timing of their decision was right, while $16 \%$ state that they should have joined earlier. Nobody states that he/she would have preferred to delay the decision.

\subsection{Information channels and social aspects}

Word of mouth played a huge role in the adoption process. $75 \%$ of responding adopters state that they had asked members (and/or the two founders) of the PV society about their experience before deciding to join, and as many as $94 \%$ report that they informed potential adopters about their own experiences.

Of the responding adopters $61 \%$ stated that they knew somebody who had joined the initiative prior to themselves (relatives: $6 \%$, friends $22 \%$, neighbours $18 \%$, acquaintances $36 \%$, nobody 
$39 \%$, multiple answers permitted), and all but one of the 67 respondents stated that they knew somebody who joined the initiative at approximately the same time as they did (relatives $16 \%$, friends $51 \%$, neighbours $31 \%$, acquaintances $66 \%$, multiple answers permitted). In the group of non-adopters who knew about the initiative, $91 \%$ of the respondents reported knowing somebody who was a member of the initiative (relatives $29 \%$, friends $27 \%$, neighbours $34 \%$, acquaintances $71 \%$, multiple answers permitted).

\begin{tabular}{lcc} 
& adopters & non-adopters \\
\hline Informative meeting & $75 \%$ & $38 \%$ \\
MR magazine & $64 \%$ & $64 \%$ \\
Acquaintances & $36 \%$ & $32 \%$ \\
MR representatives & $36 \%$ & $12 \%$ \\
MR members & $27 \%$ & $32 \%$ \\
Internet & $8 \%$ & $6 \%$ \\
\hline
\end{tabular}

Table 3: Information channels utilized by adopters and non-adopters

As indicated in Table 3, most adopters informed themselves about the initiative by attending a meeting organized by the machinery ring $-75 \%$ attended such a meeting. The next most important information channel was the quarterly machinery ring print magazine (64\%). As a primary source of information, talking to acquaintances or directly to machinery ring representatives (36\%) was less important, although these "social information channels" played a big role in later stages of the decision making process. Non-adopters who were aware of the initiative had learned about it from the following sources: the quarterly magazine (64\%), from acquaintances (32\%) and from machinery ring members (32\%).

Thus the outcomes of the qualitative interviews are supported strongly by the quantitative data. Adopters relied greatly on others as an information source, and did not refrain from reporting their own positive experiences to acquaintances. Hence word of mouth can be seen as one central success factor for this initiative. The initiators managed to bring together those interested by organising a meeting at the beginning of the project. This meant that PV adoption was the subject of many subsequent conversations among farmers. Since many farmers joined the initiative simultaneously, or at least within a relatively short time span, barriers appear to have been quite low. It seems there was a general belief that if so many others are joining, it cannot be a bad decision.

\subsection{Reputation and Trust}

In our qualitative interviews it was often reported that the good reputation of the machinery ring was a central argument for joining their PV society. Since the machinery ring is a highly trusted organisation adopters had no major worries or concerns. These qualitative results are confirmed by the quantitative data, for both adopters and non-adopters, although adopters appear to some extent to exhibit higher trust in the machinery ring.

Continuing with the analyses, we then checked whether the decision to install a PV system was directly connected to the machinery ring initiative. Here we asked adopters if they would 
also have participated in such an initiative, if it had been organized by a different institution e.g. by the municipality, a private enterprise or an electric power company. Adopters tended to agree with the statements ( 3 items, median 4.96), and also stated having already considered setting up a PV system prior to the machinery ring initiative (median 5.51). These results suggest that the initiators did not have to make much of an effort in convincing farmers about the technology. Obviously, sufficient interest already existed, and the initiative appeared just at the right time. Social networks and subsequent communication among the farmers took care of the rest.

\subsection{The effects of PV adoption on environmental awareness}

We also investigated the extent to which environmental awareness and sustainability-related motives played a role in the adoption process. From the qualitative results we know that the initiators of the PV society as well as some of the farmers were at least partly driven by ecoattitudes. In our quantitative data we find that subjective environmental awareness of farmers (self-reported on a 10-level scale, $10=$ very high) is indeed rather high. However, there appears to be no substantial difference between farmers who adopt PV and farmers who do not (median adopters 8.28 vs. median non-adopters 7.97, $\mathrm{z}=-1.014, \mathrm{p}=0.311>0.05$ ). Similarly, there is no difference between these groups regarding environmental awareness when measured more indirectly. For example, we also checked the influence of organic farming on the decision to adopt PV. In our sample, $16 \%$ of respondents were organic farmers, and although environmental awareness is significantly higher in the group of organic farmers, conventional farmers are equally likely to adopt PV. Hence environmental awareness cannot be seen as a main driver for adopting PV.

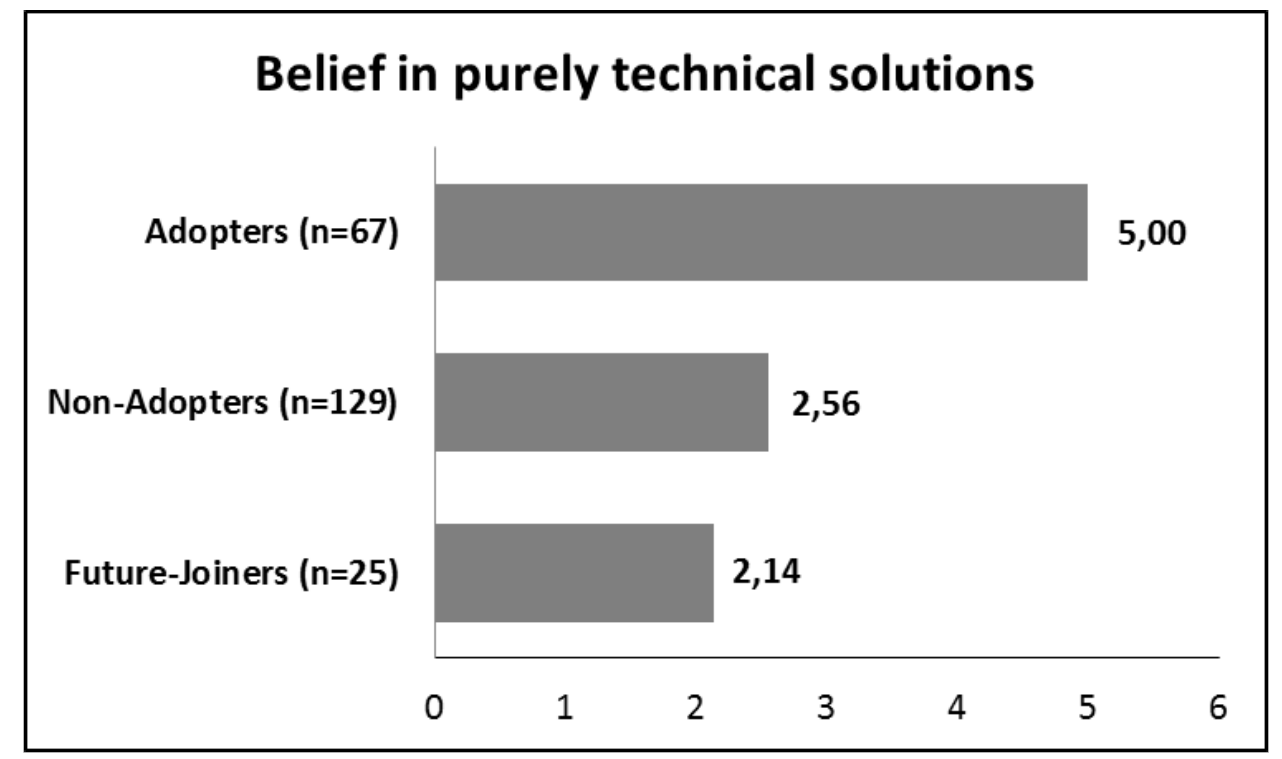

Figure 2: Respondents' belief in technical solutions to environmental problems

However, one highly significant difference was found to exist between PV adopters and nonadopters: Adopters commonly believe that technological and scientific progress can solve 
many environmental problems, such that there is no longer a need for a major change in lifestyle (median 5.00 on a 6-level scale). Here, non-adopters tend to disagree, as indicated in figure 2. The difference between adopters and non-adopters is highly significant (5.00 / 2.56, $\mathrm{z}=-6.761, \mathrm{p}=0.000<0.001)$.

Does this mean that farmers with a higher belief in technical solutions are more likely to adopt a PV system? In order to answer this question, we once more had a detailed look at the specific sub-group of non-adopters who state that they planned to join the society in the next couple of months ("future-joiners"). An analysis of their answers brought forth a surprising result: as was the case for non-adopters, "future-joiners" are also sceptical regarding the ability of technology to solve environmental problems (see table 3). Why is there such a gap between farmers who have adopted a PV system, and farmers who plan to do so? We can offer two possible explanations: (1) Farmers with weak beliefs in technical solutions adopt PV later than others, or (2) adopting PV dramatically increases belief in technical solutions.

Further analysis revealed that future adopters and current adopters, when questioned concerning their potential motives for PV adoption, ranked "fascinating technology" almost equally (median future adopters 4.62 vs. median adopters 5.07, $\mathrm{z}=-0.734, \mathrm{p}=0.463>0.05$ ). However, non-adopters, in general, are significantly less fascinated by the technology, as shown in table 1. Based on this observation and based on the well-known concept of cognitive dissonance (Festinger, 1957) we conclude that explanation (2) is more likely, and that adopting PV increases trust in technological progress, while at the same time reducing belief in the necessity for lifestyle changes. Similar phenomena, namely that behaviour affects attitudes (instead of attitudes determining behaviour) have been reported previously, e.g. in Haidt and Bjorklund (2008) or in Gigerenzer (2010). Once again, the relatively small size of the future adopters sample $(n=25)$ means that one has to be very cautious when interpreting results. Further research is clearly necessary in order to clarify the issue.

\subsection{Additional observations}

In our analysis we found several factors which do not seem to be relevant when deciding to join the PV society.

Farmers with greater experience (measured by the length of time they have operated a farm) exhibit greater concern regarding the susceptibility of the installations to extreme weather events, and have less trust in the reliability of the technology. But as discussed in the previous sections, these factors are not among the main drivers behind actual adoption.

The PV initiative is more attractive for full-time farmers than for part-time farmers. This can be seen through the high number of full-time farmers among the adopters group (75\%). Among the non-adopters the distribution is more equal (full-time 50\% / part-time $47 \%$ / no answer 3\%).

Despite the fact that agricultural work is highly dependent on energy, the desire for independence from electric power companies and related electricity charges does not play a major role in farmers' considerations. 
Furthermore, respondents (especially adopters) report a fairly high acceptance of PV plants in their communities and neighbourhoods and agree that implementing a PV system strengthens one's social standing in the community. However, PV plants are not explicitly considered to be personal status symbols.

\section{Conclusions}

The study presented in this paper offers rich insights into the motivations of PV adopters in the agricultural domain. Although farmers have rather strong eco-attitudes and report being driven by ethical considerations and inter-generational deliberations, these factors are not good predictors with respect to the adoption of photovoltaic technology. At the end of the day it is the economic aspects, not surprisingly, which dominate the decision making process. While sustainability-related initiatives can of course build on prevailing idealistic sentiments and make use of specific social mechanisms, financial incentives often need to be considered as well.

Our results furthermore point to the relevance of socio-dynamic factors. Social influence is particularly important in the information collection process, and as soon as people in one's personal environment adopt PV, barriers to adoption become much weaker. In the present case only two initiators, plus a handful of early-movers, were needed to establish a necessary framework. A suitable institutional arrangement, together with public funding and existing collaboration within the community all served to further facilitate the process, and word of mouth took care of the rest. However, it has to be mentioned that positive attitudes towards the technology had already been present. The PV initiative thus fell on fertile ground right from the beginning. Where such ground is lacking, preparation needs to be much more intensive, and even then may still be doomed to failure.

One unexpected outcome of our study is the observation that adopting renewable technology increases the belief in technology-based solutions to environmental problems, and that this might encourage the belief that additional life style changes entailing greater sustainability are no longer needed. It is clear that all such future initiatives need to be accompanied by specific educational measures in order to minimize such negative feedback effects.

Another observation is that the promotion of small-scale renewable power generation systems and respective public funding measures (i.e. the guaranteed feed-in tariff) can lead to bottomup emergence of institutional arrangements. The present case serves as a prime example of a sustainability-related bottom-up initiative which appeared at just the right time and which managed to gain momentum through the prevalence of relevant socio-dynamic factors, and the existence of an established and well-organised institution.

The small-scale structures described in the present paper exist in many countries, and there are plenty of highly motivated people willing to promote renewable energy projects within local networks. Considering the recent lack of major progress towards international climate agreements and the need for more radical transformation of our energy systems, the first and utmost governance task is to encourage such bottom-up initiatives and to support network 
structures that foster related developments. The second essential task is to continue and expand suitable funding policies. Third, adequate political mechanisms need to be developed to avoid negative rebound effects, and to utilize the added-value that bottom-up initiatives can contribute to the transition of energy supply towards renewables.

\section{References}

Bagnall, D. M., Boreland, M. (2008). Photovoltaic technologies. Energy Policy, 36(12), 4390-4396. doi:10.1016/j.enpol.2008.09.070

Bayod-Rújula, A., Ortego-Bielsa, A., Martínez-Gracia, A. (2011). Photovoltaics on flat roofs: Energy considerations. Energy, 36(4), 1996-2010. doi:10.1016/j.energy.2010.04.024

Bayrakci, A.G., Kocar, G. (2012). Utilization of renewable energies in Turkey's agriculture. Renewable and Sustainable Energy Reviews, 16(1), 618-633. doi:10-10116/j.rser.2011.08.027

Faiers, A., Neame, C. (2006). Consumer attitudes towards domestic solar power systems. Energy Policy, 34(14), 1797-1806. doi:10.1016/j.enpol.2005.01.001

Fenzl, T., Brudermann, T. (2009). Risk behavior in decision-making in a multi-person-setting. The Journal of Socio-Economics, 38(5), 752-756.

Festinger, L. (1957). A theory of cognitive dissonance. Stanford, CA: Stanford University Press.

Gigerenzer, G. (2010). Moral Satisficing: Rethinking Moral Behavior as Bounded Rationality. Topics in Cognitive Science, 2(3), 528-554. doi:10.1111/j.1756-8765.2010.01094.x

Gigerenzer, G., Gaissmaier, W. (2011). Heuristic decision making. Annual review of psychology, 62, 451-482. doi:10.1146/annurev-psych-120709-145346

Haas, R., Ornetzeder, M., Hametner, K., Wroblewski, A., Hubner, M. (1999). Socio-Economic Aspects of the Austrian 200 kWp-Photovoltaic-Rooftop Programme, 66(3), 183-191.

Haidt, J., Bjorklund, F. (2008). Social intuitionists answer six questions about moral psychology. In W. SinnottArmstrong (Ed.), Moral psychology, Vol 2: The cognitive science of morality: Intuition and diversity. (pp. 181-217). Cambridge, MA, US: MIT Press.

Jager, W. (2006). Stimulating the diffusion of photovoltaic systems: A behavioural perspective. Energy Policy, 34(14), 1935-1943. doi:10.1016/j.enpol.2004.12.022

Jarach, M. (1989). An overview of the literature on barriers to the diffusion of renewable energy sources in agriculture. Applied Energy, 32(2), 117-131. doi:10.1016/0306-2619(89)90073-1

Karkacier, O., Gokalp Goktolga, Z., Cicek, A. (2006). A regression analysis of the effect of energy use in agriculture. Energy Policy, 34(18), 3796-3800. doi:10.1016/j.enpol.2005.09.001

Malhotra, P. (2006). Energy Interventions in Rural Areas of India: Issues and Perspectives. Sustainable Development, 14, 33-45. doi:10.1002/sd

Meah, K., Fletcher, S., Ula, S. (2008). Solar photovoltaic water pumping for remote locations. Renewable and Sustainable Energy Reviews, 12(2), 472-487. doi:10.1016/j.rser.2006.10.008

Mekhilef, S., Faramarzi, S.Z., Saidur, R., Salam, Z. (2013). The application of solar technologies for sustainable development of agricultural sector. Renewable and Sustainable Energy Reviews, 18, 583-594. doi:10.1016/j.rser.2012.10.049

Ozkan, B., Akcaoz, H., Fert, C. (2004). Energy input-output analysis in Turkish agriculture. Renewable Energy, 29(1), 39-51. doi:10.1016/S0960-1481(03)00135-6

Palm, J., Tengvard, M. (2011). Motives for and barriers to household adoption of small-scale production of electricity: examples from Sweden. Sustainability: Science, Practice, \& Policy, 7(1), 6-15.

Reuss, M., Schuerzinger, H., Schulz, H. (1990). Practical application of photovoltaics in agriculture and horticulture. In T. Horigome, K. Kimura, T. Takakura, T. Nishino, \& I. Fujii (Eds.), Clean and Safe Energy Forever (Vol. 1, pp. 277-281). Elsevier Ltd. doi:10.0116/B978-0-08-037193-1.50059-8 
Smyth, M. (2012). Solar photovoltaic installations in American and European winemaking facilities. Journal of Cleaner Production, 31, 22-29. doi:10.1016/j.jclepro.2012.02.019

Statistik Austria. (2010). Agrarstrukturerhebung 2010 - Press report 10.265-118/12. Vienna. Retrieved from http://www.statistik.at/web_de/presse/064587.

Walker, G. (2008). What are the barriers and incentives for community-owned means of energy production and use? Energy Policy, 36(12), 4401-4405. doi:10.1016/j.enpol.2008.09.032 